\title{
The predictive power of approach and autonomous goal motivation for work engagement among public sector employees
}

\section{Christian Ehrlich}

Oxford Brookes University, UK

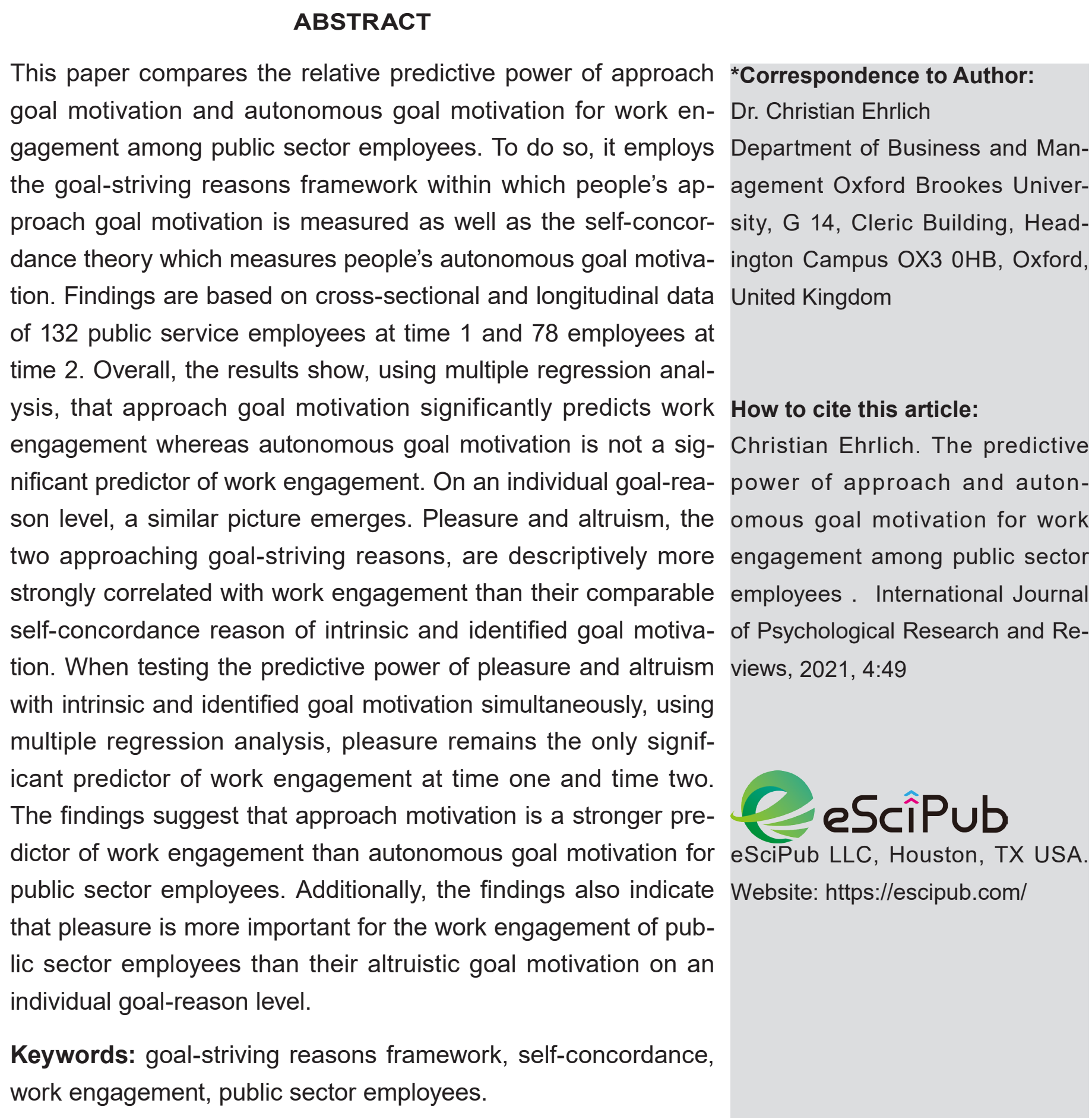




\section{Introduction}

The goal-striving reasons framework (Ehrlich, 2012, 2018, 2019; Ehrlich \& Bipp, 2016) as well as the self-concordance theory (Sheldon \& Elliot, 1999, Sheldon \& Hoon, 2007) measure the quality of reasons that underpin human goal pursuit(s). Both concepts claim that differences in the reasons for goal pursuit have implications for people's positive psychological functioning, although both categorise people's goal reasons differently.

The goal-striving reasons framework divides goal reasons into approach and avoidance reasons whereby approach reasons are defined as reasons that aim to achieve a desired outcome and avoidance reasons are defined as reasons that aim to avoid an undesirable outcome (cf. Elliot, Sheldon \& Church, 1997). The goal-striving reasons framework further distinguishes within approach and avoidance reasons whether a goal focuses on self-centred reasons (within-person reasons) or reasons outside a person (person-environment reasons) -a distinction used by many authors (Austin \& Vancouver, 1996; Eccles \& Wigfield, 2002; Ford, 1992; Ford\&Nichols, 1987). Given the distinction into approach and avoidance reasons with the further distinction into within-person reasons and person-environment reasons the goal-striving reasons framework - in its latest extended form (Ehrlich, 2018) - distinguishes between three important approaching reasons. First, goals that are being pursued because of the amount of pleasure associated with them (within-person); second, goals that are being pursued because people feel that their goals are associated with positive consequences (person-environment); and third, goals that are being pursued because they helps others (person-environment). The framework also distinguishes between three important avoidance reasons. First, goals that are being pursued because people fear to lose self-esteem if they would fail in their goals (within-person); second, goals are being pursued because people feel that if they are not successful in their goals they worry that they will struggle to make ends meet (personenvironment); and third, goals that are being pursued because failing in their goals would generally mean that people are less well-off than before (person-environment). Generally speaking, the quality of people's goal-striving reasons is better the more people strive for their most important goals out of approach reasons in relation to their avoidance reasons.

\begin{tabular}{lll}
\hline & Approach & Avoidance \\
\hline Within-person (emotional) & Pleasure & Fear of loss of self-esteem \\
Within-person (rational) & Positive consequences & Negative consequences \\
\hline Person-environment & Altruism & Necessity
\end{tabular}

Figure 1: Extended goal-striving reasons framework (Ehrlich, 2018)

Self-concordance theory applies the thinking of self-determination theory, probably one of the most influential contemporary motivational theories (Deci \& Ryan, 2000), to the specific context of people's idiosyncratic goals. It distinguishes between different forms of goal motivation ranging from very autonomous forms of goal motivation to more controlled forms of motivation. Generally, autonomous goal motivation describes a form of motivation which emanates from self-choices as opposed to external pressures which represents controlled goal motivation (Elliot \& Sheldon, 1999). More specifically, autonomous goal pursuits are 
characterised either by intrinsic motivation (the goal is inherently interesting and challenging) or identified motivation (the goal in itself is seen as important). The two controlled reasons are when people pursue their goals because of introjected motivation (the goal is pursued out of anxiety, guilt or shame) or because of external pressures (the situation demands it). People's selfconcordance is higher the stronger the two autonomous reasons are compared to the strength of the two controlled reasons.

Until today, only a few studies are available whereby the comparative predictive power of the goal-striving reasons framework and the selfconcordance theory have been tested. So far, the overall findings of these studies tentatively suggest that the goal-striving reasons framework has higher predictive power than the self-concordance theory when predicting outcome variables such as subjective well-being SWB, work engagement and burnout (Ehrlich \& Bipp, 2016; Ehrlich, 2018).

However, comparing the two models on an overall summary index ${ }^{1}$ has received some criticism in the past. One of these criticisms is that approach as well as autonomous goal motivation have been found to relate differently to outcome variables representing positive and negative psychological functioning. More specifically, approach and autonomous goal motivation are thought to be related strongly to positive psychological functioning (e.g. positive affect or work engagement) but not to variables representing negative psychological functioning. Conversely, avoidance motivation or controlled motivation have been found to relate to negative psychological functioning (e.g. negative affect, burnout) but not to positive psychological functioning (Deci \& Ryan, 2000; Ehrlich, 2019; Judge et al., 2005; Vallerand 2007).

Given these prior studies indicating that work engagement (representing positive psycho-

\footnotetext{
${ }^{1}$ This means on an overall goal-striving reasons index which takes into account the strength of people's approach motivation in relation to their avoidance motivation expressed in one single index. The same is the case for the self-concordance
}

IJPRR:https://escipub.com/international-journal-of-psychological-research-and-reviews/ logical functioning) is most strongly predicted by approach and autonomous goal motivation, the main aim of the study at hand is to test the relative predictive power of approach and autonomous goal motivation for work engagement among public sector employees. This is done on a dimensional level (approach versus autonomous goal motivation) as well as on an individual goal-reason level whereby the predictive power of pleasure, altruism and positive consequences is compared with intrinsic, identified goal motivation.

\section{Differences in the sensitivity to the influence of others between approach and auto- nomous goal motivation}

Following on from the arguments presented above around the specific importance of approach and autonomous goal motivation for work engagement, it is pertinent to highlight the theoretical differences between approach and autonomous goal motivation in more detail. This is important as it provides the theoretical narrative as to why approach motivation and autonomous motivation should differ in their predictive power for work engagement.

The main difference between the two dimensions of approach and autonomous goal motivation is hereby assumed to be around the extent to which both forms of goal motivation are sensitive to the influence of others. Here, Ehrlich (2019), for example, could show that pursuing goals predominantly for approaching goalstriving reasons is associated with low levels of sociotropy (a tendency to overly please others; Clark, Steer, Beck \& Ross, 1995) as well as the predisposition of not being influenced by others too much (Index of autonomous functioningsubscale control; Weinstein, Przybylski \& Ryan, 2012). Furthermore, pursuing goals for predominantly approaching goal-striving reasons has also been found to be associated with high levels of assertiveness (Ehrlich, 2018). All three

index which takes into account the strength of people's autonomous goal motivation in relation to their controlled motivation. 
concepts represent some form of influence of others on people's goal pursuit in the sense that people need to protect or assert themselves against the negative influence of others. On the contrary, the same studies (Ehrlich, 2018; 2019) did not find any significant correlations between self-concordance and any of these measures around the influence of others. Thus, these findings provide some empirical evidence that suggest that approach goal-motivation is more sensitive to the influence of others when compared to autonomous goal motivation.

Furthermore, looking at the core definition of autonomous goal motivation itself, it is evident that self-concordance theory only considers factors associated with the task itself as relevant (direct) factors that influence the degree to which a goal is pursued for autonomous reasons (Ehrlich,2018;2019). This is because, autonomous goal motivation is very much conceptualised as a task-inherent form of motivation which is independent from the direct reactions or influence from others. External influences are seen as detrimental to the notion of pursuing a goal for autonomous reasons and are therefore only considered within the two forms of controlled goal motivation. Admittedly, self-concordance theory is not immune to the influence of others; however, the influence of others has mostly been focussed on the impact of the (more indirect) autonomy-supporting behaviour of others (Deci \& Ryan, 2000; Ehrlich, 2019).

In this context, it is also important to note that various researchers have pointed out that feelings of independence or dependence from others during goal pursuit need to be seen as an orthogonal concept to autonomous goal pursuits (cf. Chirkov, Ryan, Kim \& Kaplan, 2003; Ryan, 1993). This is because autonomous goal pursuits are characterised by freedom and choice to which the opposite would be heteronomy, whereby one's actions are controlled by forces outside the self. Hence, feelings of dependence on others for support, guidance or any other form of reaction towards one's goals are considered unrelated to the concept of autonomy. Consequently, autonomy within goal-pursuits does not take into consideration the impact others might have on people's goal pursuits (Chirkov et al., 2003).

\section{Differences in the sensitivity to the influence of others between individual goal-reasons}

Following on from the arguments around the difference in sensitivity to the influence of others on a dimensional level, it is equally important to argue as to why individual, approaching goalstriving reasons should have higher predictive power than their respective individual, autonomous goal reasons. This provides further, more detailed insights into the specific drivers of work engagement. Of particular interest is the direct comparison between similar goal-reasons within the goal-striving reasons framework and the self-concordance theory, and how one could argue why certain individual goal-striving reasons are assumed to be more sensitive to the influence of others than the individual selfconcordance reasons. The similar goal-reasons are hereby pleasure versus intrinsic goal motivation as well as altruism versus identified goal motivation.

With regard to altruism and identified goals motivation the difference in the sensitivity towards the influence of others seems selfevident. Here, the goal-striving reason of altruism ("I strive for this goal because it helps others") touches very much on one of the core characteristics of the public sector ethos: the desire to do good and contribute to the welfare of others. As Bakker (2015, p. 723) states "People who want to make the world a better place often turn to careers in public service". Thus, the goal-striving reasons of altruism can be assumed to be very sensitive to the influence of others. Within self-concordance theory, however, this aspect does not feature very strongly, although self-concordant behaviour is theoretically linked to people's desire to do good as this satisfies the need for relatedness (cf. Deci \& Ryan, 2000; Judge et al. 2005; Sheldon \& Elliot, 1999). However, the desire to help 
others is not the same than to be satisfied in the need for relatedness. It can further be argued that identified goal motivation touches the most on people's desire to do good. Employees might pursue a certain goal because they find it important or identify with it, which in many cases is associated with the desire to help others. At the same time, identified goal motivation does not always involve pro-social behaviour, as people, quite frequently also pursue important goals for self-centred reasons. Thus, identified goal motivation might frequently involve prosocial facets, however, it is not exclusively limited to this kind of goal motivation. Hence, it can be argued that altruistic goal-striving reasons are more directly linked to doing good than identified goal motivation.

Secondly, and maybe less obvious, is the difference in the "sensitivity to the influence of others" within the goal-striving reason of pleasure compared to the self-concordance reason of intrinsic goal motivation. Here, the amount of pleasure people get from their goals can, at least partially, be caused by the reaction of others. For example, "I strive for this goal, because of the fun of it" does potentially include the possibility that the fun can be caused by the positive reactions from others. On the contrary, self-concordance conceptualises intrinsically motivated behaviour as (purely) derived from the task itself - and further praise from others would be seen as a more controlled form of motivation. Based on this argument, it can be concluded that the goal-striving reasons of pleasure is more sensitive to the influence of others than its counterpart intrinsic goal motivation.

Finally, positive consequences, the latest addition to the goal-striving reasons framework (Ehrlich, 2018) constitutes another important approach-driven goal-reason. It also allows for the inclusion of the influence of the reactions of others in people's goal-strivings reasons, which is why it should further contribute to the predictive power of the approach dimension when compared to autonomous goal motivation. However, given that there is no direct counterpart within self-concordance theory, positive consequences cannot be directly compared to the predictive power of any of the self-concordance reasons. Hence, for the purpose of comparing individual goal-striving reasons and individual self-concordance reasons they are not pertinent.

To conclude, the arguments around the differences in the sensitivity towards the influence of others lead to hypothesise that $(H 1)$ approach goal motivation should have stronger predictive power in the prediction of work engagement when compared to autonomous goal motivation. Additionally ( $\mathrm{H} 2)$, the individual goal-striving reasons of pleasure and altruism should be stronger predictors of work engagement than their respective counterparts of intrinsic and identified goal motivation within self-concordance theory.

\section{Methods \\ Procedure}

Participants were asked to complete a selfadministered, online questionnaire which required participants to state their two most important work goals (Please state your most important/second most important goal at work). For both goals, participants had to answer a set of questions about their goal-striving reasons and their self-concordance. The final part of the questionnaire contained measures around work engagement and demographical data such as age, gender and specifics about people's job roles and responsibilities. Respondents were also asked to complete a similar questionnaire a month later. Participants were monetarily rewarded and recruitment was conducted by an external market research institute. Prior to data gathering, ethical approval was obtained from the author's research institute.

\section{Participants}

This study employed a purposive sample of 132 public sector employees at time 1 , of which 78 also completed the same questionnaire a month later (time 2). This equates to a retention rate of $59 \%$. Participants were required to be in paid 
employment, hence volunteers were not eligible to take part in this study. Overall, the sample consisted of $60 \%$ female and $40 \%$ male participants with an average age of 39 years (SD $=11.95$ ). Within the sample the ratio of permanent to temporary staff was $82 \%$ permanent staff to $18 \%$ on temporary contracts. Participants worked in a variety of industries: $5 \%$ Culture, Sport and Recreation; 38.7\% Education and Research; $31.1 \%$ Health; $10.9 \%$ Social Services; $5.9 \%$ Environment; $3.4 \%$ Development and Housing; 3.4\% Law, Advocacy and Politics and $1.7 \%$ International aid. $36 \%$ reported to have management responsibilities whereas $64 \%$ did not.

\section{Measures}

Goal-striving reasons were measured by using the complete extended goal-striving reasons framework which contains 25 items, which measures the three approach and the three avoidance ${ }^{2}$ goal-striving reasons (Ehrlich, 2018). Each question was preceded by: "I strive for this goal because..." to ensure that the participants rated the reasons for their goalstriving rather than the goal as such. Example of items are: "If I fail, my self-esteem would really suffer (self-esteem)", "I get a lot of energy from it (pleasure)", "Other people do benefit from it (altruism)", "It is necessary to earn a living (necessity)", "If I fail, I would face serious negative consequences (negative consequences)" and "It is worthwhile pursuing (positive consequences)". The participants were asked to rate their answers on a seven-point Likert scale ranging from 1 (not true at all) to 7 (very true). The goal-striving reasons framework is reported to have high internal reliablitiy indices (Cronbach's alpha) ranging from .85-.88 (Ehrlich \& Bipp, 2016; Ehrlich, 2018). The approach goal motivation measure was created by averaging the means scores across pleasure, altruism and positive consquences across all goals.

\footnotetext{
2 The avoidance goal-striving reasons have been employed to test empirically whether work engagement is indeed not significantly related to work engagement. The same argument
}

IJPRR:https://escipub.com/international-journal-of-psychological-research-and-reviews/
Self-concordance was measured with Sheldon and Hoon's (2007) measure of self-concordance, which consists of four items. Each item represents one class of motivation: identified reasons ("I strive for this goal because I identify with it, even when it is not fun and enjoyable"), intrinsic goal motivation ("I strive for this goal because it is intrinsically interesting or challenging"), external pressures ("I strive for this goal because I have to or my situation demands it") and introjected reasons ("I strive for this goal because I would feel guilty, anxious or ashamed if I did not"). Participants were asked to answer each of the items for each of the two goals on a scale from 1 (not true at all) to 7 (very true). Internal reliability indices are reported to range from .75 to .81 (Judge et al., 2005; Sheldon \& Houser-Marko, 2001). The measure for autonmous goal motivation was created by averaging the means scores of intrinsic and identified goal motivation across all goals.

Work Engagement was measured using the Utrecht Work Engagemnet scale (UWES). The form is reported to have high internal reliablity (Schaufeli \& Bakker, 2003). Items have to be answered on a seven-point Likert scale ranging from 1 (never) to 7 (always; every day). Examples of items are: "At my work I feel bursting with energy" or "I am immersed in my work".

\section{Results \\ Descriptive statistics}

The descriptive statistics (Table 1) demonstrate that overall, the sample reported work engagement levels above the mid-point of the scale. The sample also reported stronger approaching than avoidance goal-striving reasons as well as stronger autonomous than controlled goal motivation. Table 1 further highlights that the three approach goal reasons are significantly correlated with engagement at time 1 and time 2, as are the two autonomous goal-reasons. As predicted, the avoidance goal

applies to the inclusion of controlled goal motivation for the self-concordance measure. 
reasons and the controlled goal reasons are not significantly correlated with work engagement, except from external pressures. However, because of the low internal reliabilities of this particular form of controlled goal motivation as well as the given focus of the paper at hand on approach and autonomous forms of motivation, external pressures was disregarded for any further analysis.

Table 1: Descriptive statistics of main study variables and correlations with engagement

\begin{tabular}{|c|c|c|c|c|c|}
\hline Variable & $M$ & $S D$ & $\alpha$ & $\begin{array}{l}\text { Engagement } \\
\text { time } 1\end{array}$ & $\begin{array}{l}\text { Engagement } \\
\text { time } 2\end{array}$ \\
\hline Engagement (time 1) & 4.78 & 1.13 & .94 & & $.69^{\star *}$ \\
\hline Engagement time 2) & 4.95 & .97 & .95 & & \\
\hline Approach (time 1) & 5.26 & 1.07 & .95 & $.50^{* *}$ & $.57^{* \star}$ \\
\hline Avoidance (time 1) & 4.58 & 1.16 & .93 & .09 & -.01 \\
\hline Autonomous (time 1) & 5.17 & 1.09 & .74 & $.35^{\star *}$ & $.33^{* *}$ \\
\hline Controlled (time 1) & 4.99 & 1.23 & .73 & $.19^{*}$ & $.27^{\star \star}$ \\
\hline Pleasure (time 1) & 4.96 & 1.37 & .88 & $.42^{\star *}$ & $.52^{\star *}$ \\
\hline Altruism (time 1) & 5.33 & 1.17 & .90 & $.46^{\star \star}$ & $.46^{\star *}$ \\
\hline Pos. consequences (time 1) & 5.50 & 1.08 & .90 & $.44^{* *}$ & $.44^{\star *}$ \\
\hline Self-esteem (time 1) & 4.23 & 1.53 & .91 & .05 & -.13 \\
\hline Necessity (time 1) & 5.24 & 1.36 & .89 & .07 & .09 \\
\hline Neg. consequences (time 1) & 4.27 & 1.49 & .89 & .09 & .04 \\
\hline Intrinsic (time 1) & 5.22 & 1.29 & .63 & $.31^{* *}$ & $.24^{*}$ \\
\hline Identified (time 1) & 5.14 & 1.23 & .65 & $.31^{* *}$ & $.34^{* *}$ \\
\hline Introjected (time 1) & 4.89 & 1.41 & .57 & .12 & .16 \\
\hline External pressures (time 1) & 5.09 & 1.32 & .54 & $.22^{*}$ & $.33^{\star \star}$ \\
\hline
\end{tabular}

Note. $N=132$ for public sector. ${ }^{*} \mathrm{p}<.05,{ }^{\star \star} \mathrm{p}<.01 . \mathrm{GSRI}=$ Goal-striving reason index; $\mathrm{SCI}=$ Self-concordance index.

The correlations in Table 2 further show that the individual goal-striving reasons have some elements in common with specific individual selfconcordance reasons. For the purpose of this paper the correlations between the individual approach and the individual autonomous goal reasons are of particular interest. The findings indicate that pleasure is most closely associated with intrinsic goal motivation and altruism is strongly correlated with identified goal motivation, although the correlation with intrinsic motivation is slightly higher.

Table 2: Correlations of individual goal-striving reasons

\begin{tabular}{|c|c|c|c|c|}
\hline Variable & Intrinsic & Identify & Introjected & External pressures \\
\hline 1) Pleasure & $.50^{\star *}$ & $.41^{\star \star}$ & $.29^{\star \star}$ & $.27^{\star *}$ \\
\hline 2) Altruism & $.64^{* \star}$ & $.57^{\star \star}$ & $.35^{\star *}$ & $.37^{* *}$ \\
\hline 3) Positive consequences & $.60^{* \star}$ & $.50^{\star *}$ & $.34^{\star \star}$ & $.39^{\star *}$ \\
\hline 4) Self-esteem & $.25^{\star \star}$ & $.35^{\star \star}$ & $.42^{\star \star}$ & $.30^{\star \star}$ \\
\hline 5) Necessity & $.19^{\star}$ & $.17^{*}$ & $.31^{* *}$ & $.44^{* *}$ \\
\hline 6) Negative consequences & .13 & $.25^{\star \star}$ & $.28^{\star \star}$ & $.32^{\star *}$ \\
\hline
\end{tabular}

Note. $N=132$ for public sector. ${ }^{*} \mathrm{p}<.05,{ }^{* *} \mathrm{p}<.01$. GSRI = Goal-striving reason index; $\mathrm{SCl}=$ Self-concordance index. IJPRR:https://escipub.com/international-journal-of-psychological-research-and-reviews/ 
Predictive strength of approach versus and autonomous dimension has been directly autonomous goal motivation on a compared with each other. The results reveal dimensional as well as individual goal- (Table 3) that the approach dimension remains striving reasons level

a significant predictor of work engagement at

Based on the correlative findings which showed that the individual approach and autonomous goal reasons are the most relevant predictors for work engagement, subsequent multiple regression analyses have been performed both time one and time two ${ }^{3}$. However, the autonomous dimension does not have any significant predictive power when entered simultaneously. Hypothesis one is therefore fully whereby the predictive power of the approach supported.

Table 3: Multiple regression analyses on sub-dimensional level predicting work engagement

\begin{tabular}{lcc}
\hline Variable & Engagement & Engagement \\
& Time 1 & Time 2 \\
& $\beta$ & $.22^{\star}$ \\
\hline Age & .15 & -.05 \\
Gender & -.01 & $.47^{\star *}$ \\
Approach & $.46^{\star \star}$ & .04 \\
Autonomous & .03 & $.34(.31)^{\star *}$ \\
\hline$R^{2}\left(\right.$ adjusted $\left.R^{2}\right)$ & $.26(.24)^{\star \star}$ & \\
\hline
\end{tabular}

Note. $N=132$ for time $1, N=78$ for time $2 .{ }^{*} p<.05,{ }^{* *} p<.01$. Coding: Gender: Male $=1$, Female $=2$.

Following on from the analysis on a dimensional level, the predictive power of the individual goalreasons has been tested using multiple regression analysis whereby pleasure, altruism and positive consequences as well as intrinsic and identified motivation have been entered simultaneously. The results show that pleasure and altruism are significant predictors of work engagement at time 1 but only pleasure remains a significant predictor of work engagement at time two (Table 4). Conversely, intrinsic and identified goal motivation were not significant for either of the two engagement measures. Hypothesis two is therefore fully supported with regard to pleasure and partially supported for altruism.

Table 4: Multiple regression analyses with specific goal-striving reasons and self-concordance reasons

\begin{tabular}{lcc}
\hline Variable & $\begin{array}{c}\text { Engagement } \\
\text { Time } 1\end{array}$ & $\begin{array}{c}\text { Engagement } \\
\text { Time } 2\end{array}$ \\
\hline Age & $\beta$ & \multicolumn{2}{c}{$.23^{*}$} \\
Gender & .15 & -.05 \\
Pleasure & -.01 & $.37^{\star *}$ \\
Altruism & $.22^{*}$ & .15 \\
Pos. consequences & .22 & .01 \\
Intrinsic & .08 & -.04 \\
Identified & -.04 & .12 \\
\hline$R^{2}\left(\right.$ adjustedR $\left.{ }^{2}\right)$ & .06 & $.38(.31)^{\star *}$ \\
\hline
\end{tabular}

Note. $N=132$ for time $1, N=78$ for time $2 .{ }^{*} p<.05,{ }^{* *} p<.01$. Coding: Gender: Male $=1$, Female $=2$.

\footnotetext{
${ }^{3}$ In this context it is important to note though, that the overall predictive power of approach motivation was similar whether 
The findings also illustrate that altruism, albeit not a statistically significant predictor for work engagement at time two, has descriptively much higher beta weights than the two selfconcordance reasons. Furthermore, drawing on prior research around a potential interaction effect between altruism and pleasure (Grant, 2008), further analyses have been conducted to test for such an interaction effect. However, no significant interaction effect between pleasure and altruism was found.

\section{Summary and Discussion}

The findings of this study provide empirical evidence demonstrating that the approach dimension has a stronger predictive power for work engagement than autonomous goal motivation among public sector employees. This, so has been argued, can be explained by the fact that the approach dimension is more sensitive to the influence of others whereas autonomous goal motivation does not consider the direct influence of others as such. Although, this explanation has not been explicitly tested in the study at hand, the findings are in line with related previous research which has provided empirical support for the argument that the goalstriving reasons framework is more sensitive to the influence of others compared to the selfconcordance theory (Ehrlich, 2018; 2019). Moreover, one of these studies (Ehrlich, 2018) provided evidence for the higher sensitivity of the goal-striving reasons framework by drawing on a sample of voluntary sector employees- a group of employees similar to public sector employees with regard to their strong desire to contribute to society and to act pro-socially (Word \& Carpenter, 2013).

Drilling down deeper, on an individual goalstriving reasons level, the two individual approach reasons of pleasure and altruism were much stronger predictors of work engagement than the two autonomous form of goal motivation of intrinsic and identified goal motivation. This is the case if work engagement is predicted crosssectionally as well as longitudinally. However, the findings also highlight the fact that pleasure is the only consistent predictor of work engagement, whereas altruism failed to significantly predict future work engagement.

Positive consequences did not act as an additional predictor of work engagement above and beyond pleasure and altruism. This is, to an extent, in line with prior research which shows that positive consequences does only marginally, but not significantly, increase the predictive power of the overall goal-striving reasons framework when predicting work engagement (Ehrlich, 2018).

Also, as postulated, the avoidance goal-striving reasons (self-esteem and necessity) as well as the controlled forms of goal motivation (introjected and external pressures) where mostly not significant. However, it needs to be mentioned that external pressures showed significant - but positive - correlations with work engagement. Still, given that the internal reliability of the external pressure scale as well as the introjected scale were poor, these two forms of goal-motivation were not explicitly considered within the paper at hand.

\section{Implications}

The theoretical implications of this study revolve, firstly, around the notion that the approach dimension within the goal-striving reasons framework provides an additional, and at this stage less well known, perspective on the factors capable of predicting work engagement beyond autonomous goal motivation. Thus, researchers interested in measuring employees' goalreasons might consider measuring people's approach goal-striving reasons rather than their autonomous self-concordance reasons when predicting employee work engagement.

With regard to the theoretical implications of the findings around the predictive power of individual goal-striving reasons, it seems important to consider that this study has been conducted with public sector employees. This group of employees is generally known for their desire to do good and wanting to have an impact on others (Bakker, 2015; Rainey \& Steinbauer, 
1999). It is therefore even more striking that pleasure remained the more relevant goal reasons compared to altruistic goal reasons for work engagement. On the basis of the findings of this study it can therefore be concluded that although pursuing goals for altruistic reasons is important for many public sector employees, it seems even more important to ensure that employees pursue goals they enjoy. Some related research supports this argument whereby it was shown that prosocial motivation is not always related to job performance (Alonso \& Lewis, 2001) but needs to be experienced as enjoyable (Grant, 2008). Ultimately, this suggests that although many public sector employees join this sector to 'do good', work goals need to be enjoyable first and foremost.

The relative importance of pleasure in relation to altruistic goal reasons also has practical implications on how to harvest the high levels of public service motivation within public sector employees. Especially in times of austerity, in combination with the fact that public sector employees are mostly not attracted to the sector by monetary incentives (Light, 2002), decision makers within the public sector need to think about other mechanisms that allow people to express their public service motivation. The findings of this study highlight the importance of employees enjoying the pursuit of their work goals - which must be seen as an additional motivation factor alongside their prosocial motivation. Furthermore, this aspect has maybe received too little attention in the public sector recently- given the overriding austerity policies in many public service institutions. Unfortunately, with the likelihood of negative economic consequences due to the UK's departure from the European Union (Tetlow \& Stojanovic, 2018), this situation may worsen in the future. Finally, it is important to mention that despite the present findings, this does not imply that the author assumes that the goal-striving reasons framework is generally superior to the self-concordance model in other industry sectors or when predicting other important outcome variables.

\section{Limitations}

Despite the contributions of this study, the findings have to be treated with caution. This is because the data is based on self-report data which might have artificially inflated the findings due to common method variance. Equally, due to the fact that participants were recruited through an external research institute the response rate remains unknown. As a consequence, a self-selection bias cannot be ruled out. Furthermore, memory effects, despite the fact that the two measurement points were one month apart, cannot also not be ruled out completely. The sample size was reasonably small which causes doubts about the representativeness of the sample in general. However, the demographics of the sample did not reveal any anomalies that would indicate that the sample differs substantially from typical public sector employees. Finally, due to the relatively small sample size within this study some of the results could have been obtained because of an overestimation of the true effect sizes potentially leading to the reporting of false positive results (Fraley \& Vazire, 2014). The likelihood that this effect influenced the results of this study is however extremely small given that the reported effect sizes are in line with the reported effect sizes from a series of related studies on the predictive power of the goalstriving reasons framework (Ehrlich, 2012, 2018; 2019; Ehrlich \& Bipp, 2016).

\section{Future areas for research}

The study also stipulates areas for future research. One of these areas is around followup studies with specific groups of professionals, particularly as the public sector is generally rather heterogeneous despite similarities with regard to a strong focus on wanting to make a difference to others or society. For example, the question arises whether the relationship between goal-striving reasons and work engagement would be the same or even 
stronger for doctors or teachers. Given that research around comparative studies on the goal-striving reasons framework and the selfconcordance model are still in their infancy, further studies need to look into the question of how those two theoretically different, though overlapping concepts can be used to complement each other - especially when used to predict outcomes variables other than work engagement. In this context it is also important to note that the individual goal-striving reason of "positive consequences" strongly correlated with engagement but did not make a unique contribution above and beyond pleasure and altruism. Thus, further research needs to look more closely into the specific contribution this goal-striving reason has to make - particularly the degree to which it captures a specific aspect of goal motivation not captured within selfconcordance theory. Finally, the goal-striving reasons framework is, so far, very much a diagnostic tool. Consequently, the question of how to change people's goal striving reasons, particularly for voluntary and public sector workers is, yet, left unanswered.

\section{Compliance with Ethical Standards}

The author declares that there is no conflict of interest, that this research has not been externally funded and that this article does not contain any studies with human participants or animals performed by any of the authors. Informed consent was obtained from all individual participants included in the study.

\section{References}

1. Alonso, P., \& Lewis, G. B. (2001). Public service motivation and job performance: Evidence from the public sector. American Review of Public Administration, 31, 363-380.

2. Austin, J.T., \& Vancouver, J.B. (1996). Goal constructs in psychology: Structure, process and content. Psychological Bulletin, 120, 338-375.

3. Bakker, A.B. (2015). A Job DemandsResources Approach to Public Service Motivation. Public Administration Review, 75, 723-732.

4. Clark, D. A., Steer, R. A., Beck, A. T., \& Ross, L. (1995). Psychometric characteristics of revised sociotropy and autonomy scales in college students. Behaviour Research Therapy, 33, 325334.

5. Chirkov, V., Ryan, R. M., Kim, Y., \& Kaplan, U. (2003). Differentiating autonomy from individualism and independence: A selfdetermination theory perspective on internalization of cultural orientations and wellbeing. Journal of Personality and Social Psychology, 84, 97-110.

6. Deci, E.L., \& Ryan, R.M. (2000). The "what" and "why" of goal pursuits: Human needs and the selfdetermination of behaviour. Psychological Inquiry, 11, 227-268.

7. Eccles, J.S., \& Wigfield, A. (2002). Motivation, beliefs, values and goals. Annual Review of Psychology, 53, 109-132.

8. Ehrlich, C. (2012). Be careful what you wish for but also why you wish for it: Goal-striving reasons and affective subjective well-being. Journal of Positive Psychology, 7, 493-503.

9. Ehrlich, C., \& Bipp, T. (2016). Goals and subjective well-being: Further evidence for goalstriving reasons as an additional level of goal analysis. Personality and Individual Differences, 89, 92-99.

10. Ehrlich, C. (2018). The development of an extended goal-striving reasons framework: Evidence for its relevance in the workplace, for its theoretical difference to self-concordance and for its buffering effect on work intensity. Journal of Positive Psychology and Wellbeing, 2, 1-23.

11. Ehrlich, C. (2019). The goal-striving reasons framework: Further evidence for its predictive power for subjective well-being on a subdimensional level and on an individual goalstriving reasons level as well as evidence for its theoretical difference to self-concordance. Current Psychology, Online First, 1-14.

12. Elliot, A. J., Sheldon, K. M., \& Church, M. A. (1997). Avoidance personal goals and subjective well-being. Personality and Social Psychology Bulletin, 23, 915-927.

13. Ford, M. E. (1992). Motivating humans: Goals, emotions, and personal agency beliefs. Hillsdale, $\mathrm{NJ}$ : Erlbaum.

14. Ford, M. E., \& Nichols, C.W. (1987). A taxonomy of human goals and some possible applications. In M.E. Ford \& D.H. Ford (Eds.), Humans as selfconstructing systems: Putting the framework to work (pp. 289-311). Hillsdale, NJ: Erlbaum.

15. Fraley R. C., Vazire, S. (2014) The N-Pact Factor: Evaluating the Quality of Empirical Journals with Respect to Sample Size and Statistical Power. PLOS ONE, 9, e109019.

16. Grant, A.M. (2008), "Employees without a cause: the motivational effects of prosocial 
impact in public service", International Public Management Journal , 11, 48-66.

17. Judge, T. A., Bone, J.E., Erez, A., \& Locke, E.A. (2005). Core self-evaluations and job and life satisfaction: The role of self-concordance and goal attainment. Journal of Applied Psychology, 90, 257-268.

18. Light, P. (2002). The Content of Their Character: The State of the Nonprofit Workforce, Nonprofit and Voluntary Quarterly, 9 (3), 6-16.

19. Rainey, H.G., and Steinbauer, P. (1999). Galloping Elephants: Developing Elements of a Theory of Effective Government Organizations. Journal of Public Administration Research and Theory, 9, 1-32.

20. Ryan, R. M. (1993). Agency and organization: Intrinsic motivation, autonomy, and the self in psychological development. In J. E. Jacobs (Vol. Ed.) \& R. Dienstbier (Series Ed.), Nebraska Symposium on Motivation: Vol. 40. Developmental perspectives on motivation (pp. 156). Lincoln: University of Nebraska Press.

21. Schaufeli, W. B., \& Bakker, A. B. (2003). The Utrecht Work Engagement Scale (UWES). Test manual. Utrecht, The Netherlands: Department of Social \& Organizational Psychology.

22. Sheldon, K.M., \& Elliot, A.J. (1999). Goal striving, need-satisfaction, and longitudinal well-being: The self-concordance model. Journal of Personality and Social Psychology, 76, 482-497.

23. Sheldon, K.M.,\& Hoon, T.H. (2007). The multiple determination of well-being: Independent effects of positive traits, needs, goals, selves, social supports, and cultural contexts. Journal of Happiness Studies, 8, 565-592.

24. Sheldon, K.M., \& Houser-Marko, L. (2001). Selfconcordance, goal attainment, and the pursuit of happiness: Can there be an upward spiral. Journal of Personality and Social Psychology, 80, 152-165.

25. Tetlow, G., \& Stojanovic, A. (2018). Understanding the economic impact of Brexit. Institute for Government. London.

26. Word, J, \& Carpenter, H. (2013). The new public service? Applying the public service motivation model to nonprofit employees. Public Personnel Management, 42 (3), 315-336. 